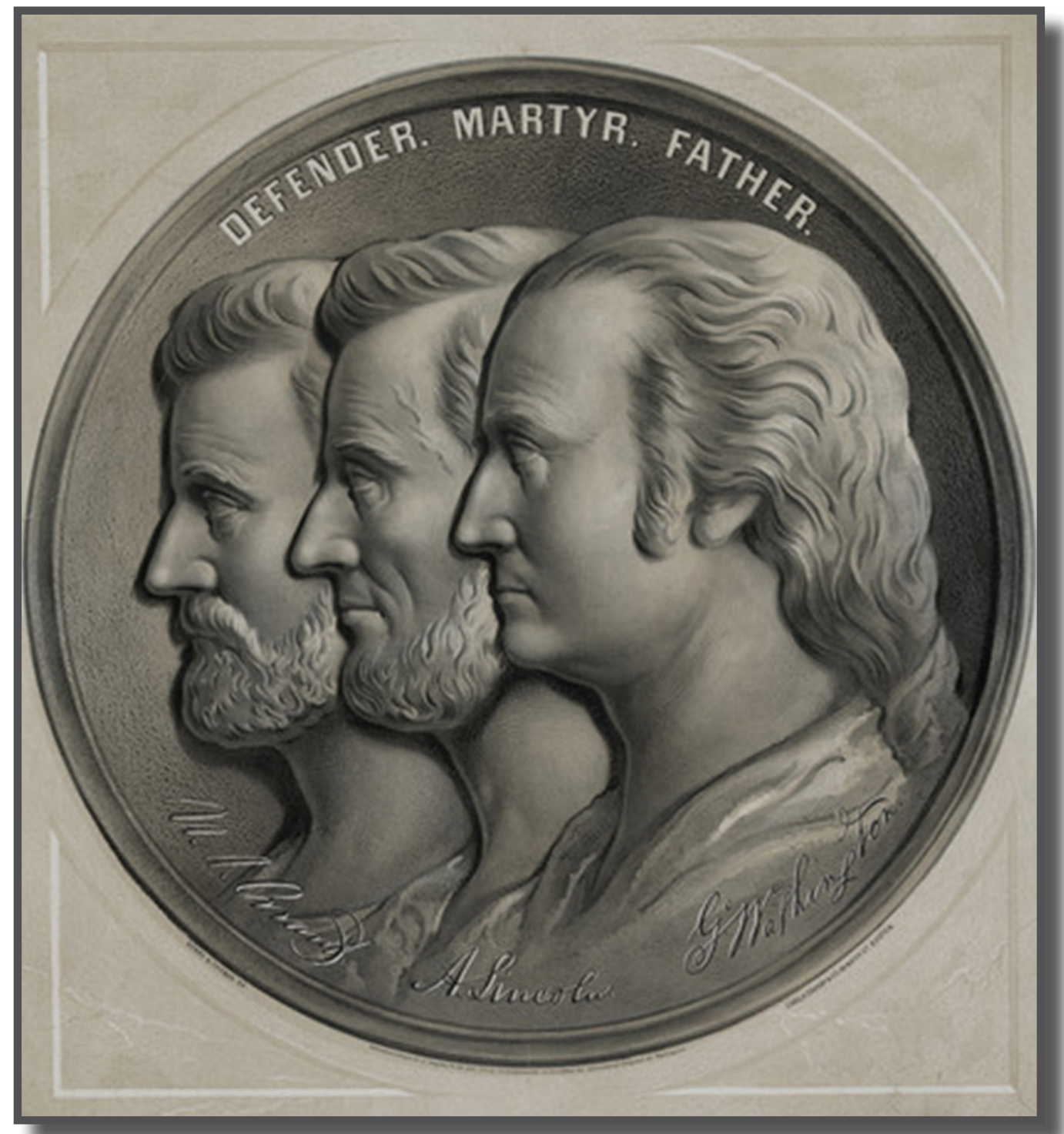

Charles H. Crosby, imagens de Ulysses S. Grant, Abraham Lincoln e George Washington. EUA. Repositório Digital Histórico Livre. http://www.historicalstockphotos.com/images/xsmall/29_ulysses_s_grant_abraham_lincoln_and_ george_washington.jpg 


\title{
O Filme Avatar Sob o Olhar do Pensamento Complexo
}

\author{
Fabiana Tavolaro Maiorino
}

\begin{abstract}
Mestre em Comunicação e Semiótica pela Pontifícia Universidade Católica de São Paulo (PUC-SP). Atualmente, é professora titular da Universidade Paulista. Tem experiência na área de Psicologia, com ênfase em Psicologia Social e na linha da fenomenologia existencial, atuando principalmente nos seguintes temas: história da psicologia, epistemologia, psicologia da educação, ética e filosofia. Desenvolve atividades de estudos dirigidos sobre Filosofia em Nietzsche.
\end{abstract}

\section{Simone de Oliveira Camillo}

Doutora em Ciências pela Coordenação dos Institutos de Pesquisa da Secretaria do Estado da Saúde de São Paulo. É docente pela Faculdade de Medicina da Fundação do ABC-FMABC/Santo André/SP. É também pesquisadora do Núcleo Interinstitucional de Investigação da Complexidade (NIIC) e do Grupo de Pesquisa em Educação e Complexidade (GRUPEC).

\section{RESUMO}

O artigo é um ensaio que objetiva realizar uma análise compreensiva sob o olhar da Complexidade de Edgar Morin, da película "Avatar", considerada como um instrumento semiótico e educacional. Enfocou-se o princípio sistêmico do Pensamento Complexo. A partir disso, o filme mostrou ser um texto fecundo, pois funciona como uma escola da vida, permitindo uma identificação e projeção dos sujeitos contemporâneos, para refletir sobre suas problemáticas psicossociais. "Avatar" revelou-se um objeto analítico rico, pois permitiu um diálogo intertextual, que explicitou a luta entre o modelo moderno inflexível e predatório, com os novos elos relacionais e éticos, mais fluidos e complexos da contemporaneidade. O diretor Cameron acusa uma inicial falência do modelo científico e utilitário e, ao mesmo tempo, a necessidade de se buscar outro modo mais humano de se relacionar com o mundo, no qual se inclui a natureza e os hábitos socioculturais em um viés sistêmico, resultando num modo de ser e estar no mundo terreno e solidário.

Palavras-chave: Cinema. Ética. Cidadania.

\section{ABstract}

The article is an essay that aims at a comprehensive analysis, under the Complexity of Edgar Morin, of the film "Avatar", considered as a semiotic and educational tool. It focuses on the principle of systemic Complex Thinking. From there, the film proved to be a fruitful text because it works like a school of life, allowing identification and projection of contemporary subjects to reflect on their psychosocial problems. "Avatar" has proved a rich analytical object, it allowed intertextual dialogue that explained that the struggle between the modern model inflexible and predatory, with new links relational and ethical, more fluid and complex contemporary. Director Cameron accuses an initial failure of the scientific and utilitarian model and, at the same time, the need to seek another more human way of relating to the world, which includes the nature and sociocultural habits in a systemic bias, resulting in a mode of being in the earthly world and solidarity. Keywords: Cinema. Ethics. Citizenship. 


\section{Introdução}

Recentemente assistimos a um fenômeno de interesse mundial por uma obra cinematográfica, produzida pelo já consagrado diretor norte americano James Cameron: o filme "Avatar", produzido a partir da cultura ocidental do século XXI, nos Estados Unidos da América em 2009. Obteve inúmeras premiações pelos efeitos tecnológicos, como os recursos em terceira dimensão. É atualmente o filme com maior bilheteria da história, superando o até então famoso filme "Titanic" (1997), do mesmo diretor. Desse modo, Avatar mostra-se como um objeto de forte e significativo apelo comunicativo, o que despertou nosso interesse em compreendê-lo sob o olhar do Pensamento Complexo.

O cinema, como mídia de alcance popularesco, comunica-se com milhões de viventes do século $\mathrm{XXI}$, tornando-se um suporte interessante aos nossos olhares de pensadores contemporâneos. Essa experiência comunicativa midiática e sensível nos revela interessantes dimensões dos diferentes modos de ser e estar no mundo na atualidade - por exemplo, a dialogia entre a preocupação ecológica no horizonte existencial do homem, e concomitantemente, a valorização do agir instrumental e técnico, que favorece a fragmentação do olhar do homem sobre o mundo.

Morin (2003) em sua proposta de reforma do pensamento ocidental comenta sobre as contribuições da cultura promovida pelas artes, incluindo o cinema, como uma nova plataforma de ser no mundo, ocupando lugar singular e fecundo para a mudança de mentalidade, pois nos remete à complexidade da condição humana.

O cinema, segundo Morin (2010), é uma das artes que melhor explicita as relações do ser humano com o outro, a sociedade e o mundo, convidando-nos a explorar de modo mais profundo a dimensão poética da vida. Portanto, além de se tornar um objeto semiótico ou gramatical, um filme pode ser considerado uma escola de vida, contendo uma função pedagógica: ensinanos a viver. Por exemplo, pode ser meio para a descoberta de si mesmo, pois o homem pode se reconhecer (identificando e projetandose) na trama das películas e desvelar suas próprias verdades.

Desse modo, para Morin (2003), compreender a mídia cinemática envolve primordialmente aproximar-se de um meio comunicativo que explicita a possibilidade da compreensão humana. Portanto, uma arte que, possível e potencialmente, revela os problemas e as dificuldades de viver em um mundo terreno. É a partir dessa premissa morianiana que se faz possível analisar um filme que aborda o futuro, pois ele oferece um plano de projeção atemporal, que permite reflexões sobre os modos de vida da contemporaneidade, sob alegorias distintas, com roupagem futurística, mas que nos convida a pensar sobre dilemas vivenciais do mundo atual.

Lidar com o filme como um fenômeno complexo implica em compreendê-lo inserido em três contextos contemporâneos: informacional, comunicacional e do conhecimento. Morin (2003) nos convida a refletir que não existe privilégio único, pois convivemos, nos e com, esses três universos concomitantemente, do aparato físico que dá suporte à informação (por exemplo, a tela do cinema ou o computador conectado à rede) ao processo de elaboração da informação do homem no mundo (por exemplo, a identificação com a personagem protagonista). Porém, Morin (2003) nos alerta frente a um paradoxo dos novos 
tempos:

Ao discurso eufórico que a tudo comunica oponho outra afirmação: quanto mais desenvolvidos são os meios de comunicação, menos há compreensão entre as pessoas. A compreensão não está ligada à materialidade da comunicação, mas ao social, ao político, ao existencial, a outras coisas (MORIN, 2003, p. 8).

Desse modo, Morin (2003) nos apresenta um alarmante aviso, em tempos "áureos" da comunicação avançada - da Internet à mobilidade mágica dos celulares - não se assegura com essas materialidades tecnológicas qualidade afetiva e humana na arte da compreensão da vida. Para isso, é preciso rever, desconstruir e superar paradigmas reducionistas, como o cartesiano, que influi, ainda hoje, nos campos institucionais da saúde e da educação.

Nessa direção, um filme, quando bem abordado, elaborado e dialogado, num contexto de ensino aprendizagem, com uma abertura epistêmica e afetiva, pode se revelar como instrumento fecundo para a compreensão humana. Pois, conforme o próprio pensador francês reafirma, o cinema com sua mídia cinemática pode promover projeções e identificações amplas sobre nossos modos de ser e estar no mundo, propiciando um novo pensamento acerca da nossa cidadania terrena. Como Morin (2010) comenta ao afirmar que o filme pode vir a ser uma escola para o exercício pleno da compreensão humana, pois:

No âmago da leitura ou do espetáculo cinematográfico, a magia do livro ou do filme, faz-nos compreender o que não compreendemos na vida comum. Nessa vida comum, percebemos os outros apenas de forma exterior, ao passo que na tela e nas páginas do livro eles nos surgem em todas as suas dimensões, subjetivas e objetivas. (MORIN, 2010, p. 50).
Deste modo, posto a relevância do filme como um objeto complexo, partimos em direção ao nosso texto olhado, a película "Avatar" e sua contextualização, pois Morin (2010) afirma a necessidade do princípio da reintrodução do conhecimento no conhecimento, ou seja, operar a inserção de um conhecimento de uma obra em seu contexto, explicitando o tempo e o espaço de sua produção. Assim como o diálogo intertextual dessa obra com outras, que possuem princípios organizadores semelhantes.

Segundo Knight e Kninght (2003), "ler" um texto fílmico implica em realizar uma análise do gênero a oqual este pertence. No caso de "Avatar", podemos elencar várias películas que retratam o gênero de ficção, com matizes de romance e aventura, tais como : a saga "Matrix", "eXistenZ", "Os Substitutos", "A Ilha", "Blade Runner", "Transfer", entre outros. Assim como "Matrix" (1999), recente sucesso do cinema norte americano, "Avatar" também pode ser lido como uma narrativa de busca que combina temas clássicos, tais como a descoberta, a iniciação, a total auto realização do herói e o triunfo do bem sobre o mal.

Com relação aos papéis comunicacionaisenunciativos trazidos por "Avatar", podemos identificar como emissor (definido como o lugar discursivo que produz o texto), as vozes enunciativas, que produzem o filme em seus diferentes aspectos: da montagem das cenas à sonografia. Já como receptores possíveis (aqueles lugares discursivos que recebem o texto), encontramos as escutas sociais dos adolescentes e os adultos jovens da contemporaneidade, primordialmente, da cultural ocidental. Podemos especificar que são principalmente, aqueles que apreciam o uso das novas tecnologias, visto que o filme se 
utiliza de um forte chamamento tecnológico em sua exposição: o uso de telas em 3D (três dimensões), além dos efeitos cinemáticos avançados, trazidos pelas imagens explícitas no filme (BRONCKART, 1999).

Temos a convivência desses receptores potenciais com os discursos sociais provindos desse lugar do emissor, pois ambos constituem-se no século XXI, tempo em que a comunicação e a revolução da informação são temáticas recorrentes. Portanto, é possível o diálogo entre eles, pois os emissores possuem e se utilizam de semelhantes modos discursivos e valorativos para comunicarem seu produto (o filme) para o possível receptor ocidental da atualidade (BRONCKART, 1999) .

O filme relata uma história épica no ano de 2154 d.C. de dominação humana frente ao mundo de Pandora. Protagonizado por Jake Sully, soldado que ficou paraplégico após uma batalha na Terra. A partir disso, ele é escolhido para compor o programa Avatar, substituindo seu irmão gêmeo, agora falecido. Jake viaja para o planeta Pandora, onde se depara com um cenário pitoresco: animais extraordinários e estranhas formas de vida. Essa lua extraterrena é habitada por um povo primitivo chamado $\mathrm{Na}$ 'vi (composto de seres com 3 metros de altura, coloração azul e muito fortes fisicamente), que são arraigados à natureza e à sua cultura mítica. Em contraponto, a mineradora humanoide RDA quer explorar Pandora para conseguir um rico minério (Unobtainium). Para isso, uma equipe de cientistas, coordenados pela Dra. Grace Augustine, cria o programa Avatar, para construírem seres semelhantes aos na'vis, governados mentalmente pelos humanos. Nessa empreitada de colonização dos na'vis, Jake conhece uma nativa chamada Neyriti, pela qual se apaixona. O filme relata uma história épica e dramática entre os humanos e os na'vis, dos primeiros em busca de riqueza e do outro lado, desejo dos nativos pela permanência do equilíbrio ecossistêmico de Pandora. Segue sua ficha técnica, divulgada nas mídias sociais e sites sobre cinema:

Quadro 1 - Ficha técnica: Avatar

Diretor: James Cameron.

Elenco: Sam Worthington, Sigourney Weaver, Michelle Rodriguez, Zoe Saldana, Giovanni Ribisi, Joel Moore.

Produção: James Cameron, Jon Landau.

Roteiro: James Cameron.

Fotografia: Mauro Fiore.

Trilha Sonora: James Horner.

Duração: $162 \mathrm{~min}$.

Ano: 2009.

País: EUA.

Gênero: Ação.

Cor: Colorido.

Distribuidora: Fox Film.

Estúdio: Twentieth Century Fox Film Corporation/Lightstorm Entertainment/Dune Entertainment/Ingenious Film Partners.

Classificação: 12 anos.

Fonte: Avatar (2012).

Como há pouco apontado, utilizamos o filme "Avatar" como suporte de discussão ética e social na experiência de um contexto de ensino-aprendizagem, que tem sido um recurso psicopedagógico usado por muitos pensadores das ciências humanas e educacionais, que reafirmam o lugar das obras audiovisuais como recursos potentes na educação.

A escolha por essa película se deu devido ao interesse acadêmico e às inquietações das duas pesquisadoras docentes, que ministram conteúdos programáticos nos cursos de psicologia e de enfermagem em duas universidades particulares da Grande São Paulo. Diante dessa prática docente, relacionaram o filme com temas programáticos 
das disciplinas de Relacionamento Interpessoal, Ética e Cidadania. Desse modo, decidiu-se construir uma reflexão complexa e sensível para contemplar as temáticas trazidas pelo filme, usando-o para propor uma compreensão, através do Pensamento Complexo, da condição terrena. Para isso, analisaremos o modo de pertencimento humano e nativo ao mundo complexo de Pandora, o cenário imaginário em que reside o drama de "Avatar".

Essa reflexão partiu da visão da Complexidade, arquitetada pelo pensador Edgar Morin, que tem se colocado à mercê do seu tempo histórico na busca intermitente por uma reforma do pensamento humano na contemporaneidade. Petraglia (2002) apresenta-o como pensador transdisciplinar, autor da chamada Epistemologia da Complexidade, que irá se opor ao paradigma tradicional do cartesianismo, com os traços costumeiros do pensamento linear, reducionista e disjuntivo.

A Complexidade, em sua proposta ontológica e epistêmica, parte do que o próprio Morin (2010) denominou como um processo em que os componentes constituem um todo, seja ele social, cultural, afetivo ou econômico, constituindo "[...] um tecido interdependente, interativo e inter retroativo entre as partes e o todo, o todo e as partes [...]" (MORIN, 2010, p. 14). Dessa maneira, a Complexidade para Morin (2005, p. 13) é "[...] tecido de acontecimentos, ações, interações, retroações, determinações, acasos, que constituem nosso mundo fenomênico".

A educação tem sido o cenário privilegiado de atuação de Morin, que tem contribuído continuamente com a reformulação dos saberes, propondo uma reviravolta no processo de ensino-aprendizagem. É preciso, segundo o pensador francês, propor um modo mais humano e compreensivo para abordar o desenvolvimento cognitivo, social, cultural, espiritual e cosmológico do homem na relação com a sua morada co-existencial, a Terra. Aprendemos a compreender o outro e ao mundo, ao viver e depender dessa comunidade terrena e do seu lócus, assim, dependendo uns aos outros. Somos unidos - homens, objetos, natureza, animais, coisas, teorias e instrumentos - por elos sutis de organicidade e pelo dever, invisível e existencial, de nos cuidar, em direção a uma cidadania plena, global e terrena.

Essa via de compreensão da complexidade parte de uma frente teórica epistêmica em que se fazem presentes diferentes influências, como a visão cibernética de Weaver, a teoria da informação de Shannon nos anos de 1950 e a teoria da linguagem contemporânea de Wittgenstein, fora as contribuições da psicologia social francesa e da antropologia pós estruturalista (MORIN, 2002).

Morin (2010, p. 93-96) empreende sete princípios organizadores para consolidar a reforma do pensamento proposta por ele, os quais são responsáveis pela ligação efetiva para rumarmos em direção a uma cidadania terrena e hominizada. São eles respectivamente: (1) princípio sistêmico ou organizacional, "[...] como aquele que liga o conhecimento das partes ao conhecimento do todo [...]"; (2) princípio hologrâmico, "[...] que põe em evidência este aparente paradoxo das organizações complexas, em que não apenas a parte está no todo, como o todo está inscrito na parte [...]"; (3) princípio do circuito retroativo, no qual se supera a linearidade, e compreende-se que os fenômenos possuem uma causalidade circular e autorreguladora, ou seja, "[...] a causa age sobre o efeito, e o efeito age sobre a causa [...]"; (4) princípio do circuito recursivo, no qual "[...] o circuito gerador em que os produtos e os efeitos, 
são eles mesmos, produtores e causadores daquilo que os produz [...]"; (5) princípio de autonomia e dependência, no qual "[...] os seres vivos são seres auto organizadores, que não param de se auto reproduzir e, por isso mesmo, dependem da energia para manter sua autonomia [...]"; (6) princípio dialógico, de inspiração grega de Heráclito, considerado pai da dialética, no qual se unem dois princípios que poderiam se excluir, porém indissociáveis em um mesmo plano real e (7) o princípio da reintrodução do conhecimento sobre todo conhecimento, quando acontece a restauração do sujeito, explicitando um problema cognitivo, importante, que revela que "[...] todo conhecimento é uma reconstrução/tradução feita por uma mente/cérebro, em uma cultura e época determinadas [...]".

Diante da amplitude do nosso objeto de estudo e da Teoria da Complexidade de Edgar Morin, optou-se nesse ensaio dialógico por selecionar um eixo analítico compreensivo e de interessante abrangência, sendo denominado pelo próprio pensador como raiz da complexidade (2008): o princípio sistêmico ou organizacional.

\section{A Compreensão Sistêmica de Avatar pelo olhar da complexidade}

Morin (2010, p. 93) elege o princípio sistêmico ou organizacional, "[...] como aquele que liga o conhecimento das partes ao conhecimento do todo [...]". Para o autor, foi imprescindível observar a teoria dos sistemas e a cibernética para constituir esse fundamento da complexidade.

A noção de sistema não é simples, muito menos absoluta. A denominação de sistema comporta noções de relatividade, dualidade, multiplicidade, cisão, antagonismo, ou seja, para problematizar de forma inteligível qualquer sistema, não se deve reduzi-lo a apenas uma dessas noções, é necessário ter sempre a perspectiva do Pensamento Complexo (MORIN, 2008). A partir dessa compreensão, é que Morin (2005) nos revela três aspectos contraditórios e necessários que compõe uma visão sistêmica. Seriam eles: (1) centralidade da noção de sistema como um todo complexo, que não se reduz a simples soma das partes constituintes; (2) considerar a noção de sistema como algo fantástico, sem a reduzir ao aspecto formal e (3) situar o sistema numa dimensão transdisciplinar, ou seja, contemplando os fenômenos de associação e organização.

Podemos transpor nossos olhares para Pandora e iniciar nossa análise compreensiva sob o viés sistêmico, ressaltando que no filme "Avatar", os emissores (encarnado, nesse caso, na equipe de produção e direção do filme) nos apresentaram aquele planeta distante como um sistema aberto, com trocas vivas e orgânicas que animam o cotidiano terreno daquele solo. Ao mesmo tempo, Pandora representa um sistema estável, pois mantém sua identidade, ou seja, é reconhecido por seus habitantes, e inclusive pelos estranhos, como os humanos, que o nominam de assustador. A partir disso, Pandora revela-se como aquela caixa mítica grega que se abre e nos convida a mergulhar no inesperado e assustador mundo da dialogia cósmica, repleta de horrores e belezas. Há o traço da caoticidade, que desestrutura e aniquila, com sua natureza viva e auto protetora, convivendo com o calor da esperança amorosa e da solidariedade ética e relacional de uma tribo nativa, com sua mítica festiva e cuidadosa.

Vivemos em Pandora, aquele universo mágico e colorido desenhado em movimentos imagéticos e sonoros nas telas de cinema, que 
nos revela nosso possível duplo, estampado no medo que temos das nossas facetas mais odiosas, que tem marcado nossos tempos com eventos horripilantes, pois como não os caracterizar assim, diante dos genocídios recentes na África. Mas ao mesmo tempo, nosso duplo também nos revela nossas faces solidárias e afáveis, que se mostram em fenômenos poéticos dos novos tempos, como, por exemplo, nas reuniões entre jovens para lutarem contra a devastação ecológica, nos movimentos para mantermos uma economia sustentável no planeta, ou ainda, na solidariedade trazida em momentos de conturbação ecológica, como os terremotos ou maremotos recentes na Ásia.

Temos Pandora como a projeção de um futuro distante em um possível presente, como um sistema poroso e que vive dinamicamente com sua natureza, em um devir vivaz e instável. Pandora não seria um sistema fechado, pois como Morin (2005) salienta, os sistemas fechados são aqueles que se encontram em total homeostase, ou seja, as trocas de energia e matéria com o exterior são nulas.

Em "Avatar", Pandora apresenta-se com uma natureza singularizada pela sua qualidade entrelaçada e interdependente entre os seres nativos, os chamados na'vis, os animais, a floresta e com os humanos, recém chegados. Dentre as várias tribos, o filme enfoca a organização dos Onamaticayas, no qual Jake Sully é inserido como membro novo para aprender a ser um deles.

Podemos usar duas cenas típicas para iluminar dois traços do princípio sistêmico aqui abordados, ou seja, sua abertura e interdependência. Segue sua descrição:

$\mathrm{Na}$ primeira cena escolhida (aos 32 minutos e 31 segundos do filme), Neyriti, quando conhece Jake, fica emocionalmente incomodada, pois teve que intervir num momento em que o humano estava sendo atacado por cães ferozes de Pandora. Nesse instante, Neyriti interfere no equilíbrio ecossistêmico daquele lugar da floresta e acaba matando um dos animais. Sua ação naquele pedaço da natureza de Pandora romperia com a filosofia complexa dos na'vis, na qual todos os seres estão interligados, e quando se interrompe esse elo, rompe-se com a integridade e equilíbrio do planeta.

Existe, ainda, outra cena elencada (aos 65 minutos), na qual se ilustra a relação de Jake com Neyriti. Depois de passar por um aprendizado cultural e étnico, a nativa reconhece que Jake está pronto para ser um na'vi. Os dois estão caçando e ele mata um animal com sua flecha. A partir disso, Jake reage como um nativo, fazendo uma oração e proferindo as seguintes palavras: "Eu vejo você, meu irmão, e o agradeço, sua alma irá retornar para Eywa, mas seu corpo permanecerá aqui, para então servir de alimento ao povo na'vi".

Nessas passagens, começamos a localizar os valores da cultura do personagem dos na'vis. Há a valorização da integração dos nativos com a natureza, animais e outros seres de Pandora, assim como a valorização da solidariedade entre eles e a natureza, a lealdade e o respeito com o lugar em que vivem.

Morin (2005) ressalta ainda a importância da informação em movimento para a compreensão de um sistema. Ele afirma que a apreensão de sentido gerada em uma rede de informações favorece uma abertura comunicacional, que não é fator suficiente, mas necessário para a arte da compreensão. Por exemplo, em Pandora e sua biosfera encontramos um sistema aberto, como já apresentado, na qual existe uma rede intrínseca de informações que se retroalimentam. Tudo em Pandora 
se comunica. As plantas, os pássaros, as cachoeiras, os animais, entre outros. Essa intercomunicação em rede é presenciada e "medida" pelos humanos, numa tentativa cartesiana de explicação empírica e linear. Para ilustrar isso, podemos citar a cena em que a Dra. Augustine mede a energia eletroquímica entre as raízes da densa floresta do planeta, explicitando que existe vida pulsando em rede em Pandora (aos 24 minutos e 20 segundos). Esse dado informativo por si só pode colaborar para uma suposta compreensão dos humanos sobre o modo de vida em Pandora, porém isso não ocorrerá.

Existe em Pandora um sistema aberto, que se auto-eco-organiza, conforme Morin (2005) nos ensinou, ao comentar que esse traço está presente em sistemas abertos, vivos e que permitem trocas de energia e matéria. Essa abertura promove, dialogicamente, um fechamento, pois é somente a partir dela que os seres em Pandora se reconhecem e a identificam como sua morada co-existencial, ou seja, existe um relativo equilíbrio também que permite que o planeta se mantenha unificado. Em sistemas auto-eco-organizados, como Pandora, existe uma relação saudável com o desequilíbrio, ele constitui a busca pela organização, em busca de estabilidade e continuidade (MORIN, 2005).

Podemos vislumbrar esse rico e complexo movimento observando a natureza de Pandora em relação com a antropologia do lugar: há uma interdependência instável entre os elementos constituintes, entre os nativos, entre as criaturas animais que os assolam, as mudanças naturais, os lugares do sagrado, o movimento das sementes da alma de Pandora.

Pandora também nos alegra com sua cromaticidade. $\mathrm{O}$ azul distoante por todo o filme nos joga num cenário onírico, embebedado da natureza estonteante daquele planeta, dos animais ora grotescos, ora mansos e solidários com os nativos. Quem não desejou voar num Banshee e tocar as sementes da alma de Ewya, ou mesmo, ser um na'vi correndo e caindo por sobre as cachoeiras das Montanhas Aleluias?

$O$ regime das trocas entre os elementos constituintes nesse sistema vivo de Pandora é sinalizado durante toda a película. $\mathrm{Na}$ elaboração enunciativa do filme tomou-se um cuidado estético ao simbolizá-la com o chamado Tsu helu (o elo). Esse elo está imageticamente disposto no filme em diferentes cenas, basta observar a forma física e orgânica dos Na'vis, que possuem corpos azuis, fortes e bem torneados, com um rabo enorme, que realiza um elo ontológico com as coisas da natureza, tais como os animais alados, as árvores sagradas, conotando a força dessa ligação.

Há de se destacar uma das últimas cenas, em que Jake em sua forma humana está nu, deitado próximo à Árvore Sagrada, para um ritual de passagem para a permanência no corpo de um ser na'vi. Nesse ritual, há a ligação com a força de Ewya e com os seres nativos em rede, o que revelaria um novo nascimento de Jake, o que no filme se ilustrou com a enunciação do Wake Up (que significa o despertar, às 2 horas, 33 minutos e 54 segundos do filme).

Essa marca das trocas (ligação com dos na'vi com os seres de Pandora) está permeando todo o filme, inclusive no arado humano. Por exemplo, nas conexões, nos dispositivos quânticos que controlam os avatares, nos biolaboratórios da Dra. Augustine. Porém, há de se destacar um movimento intrigante: a conexão dos humanos com os seus avatares não é contínua, existem desconexões repetidas vezes, talvez enunciando um movimento contemporâneo terreno, o qual 
cada vez mais fica mais difícil de realizar: o da desconexão com o mundo da comunicação. Já em Pandora, ocorre o contrário, pois a conexão dos na'vis com a natureza e de todo esse ecossistema acontece continuamente, numa rede instável e viva.

O tema da conexão eco-organizadora em Pandora pode ser imageticamente ilustrado por diferentes e intrigantes cenas no filme. Por exemplo, naquela em que os na'vis se ligam com os Banshees, seus animais de poder, a conexão dos nativos com a Árvore das almas, que conecta esses seres com toda a rede de força do planeta. Podemos ainda apontar a força dessa temática numa das cenas finais, em que os nativos de diferentes clãs só conseguem reaver Pandora quando essa grande rede de energia se comunica, ou seja, se conecta, e Ewya toma partido e mobiliza as forças naturais para combater a ambição humana (às 2 horas e 18 minutos do filme).

No mundo mítico de Pandora, explicita-se a visão de mundo sistêmico, interdependente e solidário, pois os seres de Pandora acreditam que "[...] a energia que flui de todas as coisas vivas é só emprestada e deve ser um dia devolvida [...]". O nativo não se coloca acima dos demais seres da natureza, pois acreditam que são apenas parte de um todo. Os seres azuis respeitam os outros seres, como respeitam a sua espécie. O que importa é o equilíbrio interativo e respeitoso entre tudo o que é vivo.

O povo de Pandora não usa a razão utilitarista para explicar a sua existência, como os humanos no filme o fazem, e diríamos, no cotidiano atual e presencial também. A cena que mostra todos de braços dados em uma comemoração simboliza essa conexão entre todos os indivíduos e a importância dada ao coletivo e ao todo. Todas as decisões e resoluções da espécie são tomadas frente à comunidade e em respeito à energia da qual eles fazem parte. Há uma visão solidária terrena do mundo na abordagem de Cameron para Pandora, em contraposição ao antropocentrismo do homem no novo planeta.

Podemos afirmar que, em Pandora, a cultura na'vi possui uma disponibilidade e abertura diante o Outro, buscando uma maior solidariedade, condição essencial para promover a arte da compreensão terrena. Para ilustrar essa possibilidade observa-se (aos 41 minutos e 18 segundos do filme) o contrato intercultural entre Jake (representando o líder do povo do céu, homens) e os $\mathrm{Na}$ 'vis (representados pelo pai e mãe de Neyriti). Nessa cena, é oferecido aos nativos uma oferta cultural de Jake Sully, os ensinamentos de sua "tribo", sobre suas técnicas militares. Aqui se revela o objeto de valor de troca oferecido ao povo de Pandora.

Jake chega junto com Neyriti à Grande Árvore dos primitivos, onde ocorre uma acolhida desconfiada, pois os líderes dos na'vis não queriam mais o "povo do céu" (humanos) em seu território. A Xamã, mãe de Neyriti, avalia Jake em seu avatar para sancionar ou não a sua permanência junto a eles. A Tsa'hik, como é chamada essa mulher com poderes místicos, vai avaliar a sorte de Jake para receber a mensagem de Ewya, a grande alma mantenedora da energia cósmica de Pandora. Jake emite um convite sedutor, dizendo a ela que veio para aprender. A mulher na'vi responde dizendo que "é difícil encher uma taça que já está cheia". O humano em sua roupagem nativa azul retruca que sua "taça está vazia" e se apresenta como um guerreiro do clã dos homens do céu, chamado de Cabeças de Pregos. Nesse instante (aos 46 minutos do filme), o líder dos na'vis interrompe sua esposa, a xamã, e afirma que será interessante aprender com Jake os modos de ser desse clã, sancionando sua 
permanência junto à tribo primitiva dos seres azuis. Nesse contexto é oferecida ao humano uma possibilidade de compreensão. Veremos que, num primeiro momento, esse contrato fracassará, pois Jake estará ainda implicado com interesses escusos, tais como denunciar os pontos fracos da tribo Onomaticaya para os militares em sua base.

A visão humana em Pandora pode ser identificada como o lugar do estrangeiro, denominado como "o povo do céu", que gera, como ilustrado aqui, a recusa dos nativos, que já tiveram experiências interculturais desastrosas. Essa tribo humana é figurada pelo jovem Jake Sully, que lidera os "cabeças de pregos", referência simbólica à rigidez da natureza humana. Podemos realizar aqui uma reflexão da condição humana em Pandora, sinalizando que esta sofre do que Morin (2005) denominou de patologia da razão. Quadro tipológico marcado pelo viés instrumentalista, que busca manter uma coerência racionalizadora sobre suas atividades, ou seja, o homem em "Avatar" é alimentado apenas pela ambição, diante da riqueza e do controle territorial. Em função disso, constrói e age diante o mundo, no sentido do controle das variáveis, sem lidar com a incerteza e a caoticidade que a vida em movimento desperta. Podemos ilustrar a valorização técnica-racional em várias imagens do filme, tais como: o cuidado com o arsenal exploratório mantido pelos militares; o manuseio seduzido das armas robustas em verdadeiros simulacros de guerra; o contexto do biolaboratório, altamente tecnológico; assim como as naves e helicópteros equipados com um arsenal bélico impressionante. Toda uma engrenagem técnico-científica em busca de domínio e sucesso da missão implementada.

Há de se destacar uma cena em que Jake encontra-se em situação de apropriação das competências pragmáticas com Neyriti (aos 64 minutos do filme), e afirma em seu vídeo diário que "a linguagem dos na'vis é chata". Compara a sua aprendizagem com o processo mecânico de desmontar uma arma, onde o que importa é a repetição dos passos. Essa lógica trazida pelo filme nos remete ao império da visão técnica, fragmentada e mecânica predominante na Modernidade, instaurada pelo pensamento cartesiano aliado ao positivismo criminoso levado às últimas consequências.

Pandora intertextualiza, portanto, a história recente do Ocidente europeu, retomando a América colonizada do século $X V$, convidando-nos, por exemplo, a reviver nossa história brasileira, em que num processo agressivo de dominação europeia, alimentado pelo enriquecimento, pela exploração das nossas matérias-primas, matou e ignorou a solidariedade com a terra e seus nativos. Fizemos das Américas na Modernidade o palco de um combate desleal e sangrento, que até hoje ainda ressoa em nossos olhares, diante da luta desigual entre os poucos nativos que temos e os interesses latifundiários.

O filme Avatar e o modo de existir em que o homem é relatado nos convidam, conforme Morin (2005) nos ensinou, a compreender que nossas sociedades humanas são máquinas não triviais, pois elas necessariamente lidam com eventos imprevisíveis, ou seja, passam e conhecem diferentes momentos de crises sociais, culturais ou econômicas. Diferente de uma máquina trivial, em que podemos conhecer todos os circuitos de entrada e saída, o homem e suas sociedades não podem ser descritas como um sistema fechado e previsível. Viver uma crise significa aprender a lidar com as incertezas que dela decorrem, pois os controles falham, a ordem é desordenada e os conflitos atualizam-se. 
Esse é o momento em que vivemos, polemizado e visualizado no cenário futurístico de "Avatar", mas que nos reconduz ao presente em uma era de transição e crises multifacetadas, em que a racionalização se mostra como um modo infecundo de lidar com as incertezas e as novidades humanas e sociais. É preciso provocar uma abertura ontológica e societal para que possamos enfrentar os novos tempos com maior solidariedade, ética e compreensão planetária, repletos de desafios e novos modelos co-existenciais.

\section{Considerações Finais}

Na pós-modernidade, o filme "Avatar" mostrou ser um texto projetivo rico, pois revela a enunciação da dialogia, como a convivência de diferentes modos de ser e estar no mundo, ou seja, de um lado temos um sistema vivo, aberto, contagiante e integrado organicamente dos $\mathrm{Na}$ 'vi e de outro, o modo fragmentado e utilitarista dos humanos, com enfoque predatório e instrumental. Entretanto, é também possível visualizarmos a existência de um modo de se fazer ciência mais humano e respeitoso. Dessa maneira, presenciamos uma dialogia viva e tenaz projetada naquele planeta distante de nós.

Pandora, um planeta a priori distante, em um tempo futurístico, transforma-se aos poucos na película Avatar em nossa morada co-existencial: a Terra. Um lugar repleto de contradições insolúveis, que acorda a cada dia colhendo e revivendo os frutos de décadas, e por que não dizer, de séculos de ações exploratórias irresponsáveis e aniquiladoras, sem se ater aos elos de interdependência entre os seres constituintes desse organismo vivo e dialógico.
Nesse sentido, o filme Avatar se faz intrigante e, por isso, seu sucesso avassalador, porque nos remete indubitavelmente a uma história familiar e cosmológica sobre a nossa identidade terrena.

O filme implica-nos frente às nossas questões éticas, aos dilemas coexistenciais frente à crise da relação do homem com a natureza, às consequências funestas dessa ação predatória de tempos modernos que não cessaram. Assim como também a falta de compreensão, os fundamentalismos irracionais e mentecaptos e a violência decorrente desses cenários complexos.

Pandora traduz o momento de transição que vivemos com a convivência de modelos intersubjetivos e sociais distoantes e insolúveis. Assim como também nos fornece material figurativo para mobilizar-nos em direção às novas responsabilidades existenciais e terrenas que nos cabe, ao habitarmos nosso universo antro-bio-fisico e cultural, do qual somos parte em um todo hologramático, em constante movimento, num sistema aberto e vivo.

O que talvez ainda não nos demos conta é que a beleza singular de Pandora não está longínqua, e se encontra ainda em nossos pertences terrenos, nosso planeta interligado com nosso ser cósmico, com nossa galáxia. E, portanto, ainda nos consagra com essa diversidade poética e frágil, mas que precisa urgente e afetivamente ser cuidada e respeitada. Somente assim poderemos lidar com uma vida terrena mais equitativa social e calorosamente afetiva em nosso cotidiano humano e sistêmico. Sem esse cuidado com nossa condição terrena e finita, a reforma do pensamento se faz inviável. Então, no lugar privilegiado do educar, faz-se necessário mobilizar os olhares institucionais e humanos para um novo modo de se compreender o mundo. 
É preciso educar os seres humanos para uma nova relação com a existência ecossistêmica, reconsiderando os conceitos de dever e agir mediante ao estar no mundo com suas finitas possibilidades existenciais e naturais.

Dessa forma, será necessário consideramos um projeto de vida contemporâneo mais flexível e possível para deixar o homem ir e vir no seu labirinto co-existencial, constituindo, então, uma morada rizomática em permanente metamorfose e em sintonia com as outras dimensões da vida, incluindo a natureza. Desse modo, finalizamos, recomendando a necessidade da compreensão da existência como uma balsa e não mais como uma prisão panóptica. Para isso, faz-se necessário investir em políticas públicas de saúde e educação, compreendendo que existem outros recursos, como os filmes, que podem vir a educar crítica e solidamente nossos sujeitos.

\section{Referências}

AVATAR. Wikipedia. Disponível em: < http://pt.wikipedia.org/wiki/ Avatar_\%28filme\%29>. Acesso em: 2 nov. 2012.

BRONCKART, Jean. Atividade de linguagem, textos e discursos: por um interacionismo simbólico. São Paulo: EDUCA, 1999.

KNIGHT, Débora; KNINGHT, George. Gênero real e filosofia virtual. In: IRWIN, W. Matrix: bem vindo ao deserto do real. São Paulo: Madras, 2003.

MORIN, Edgar. A cabeça bem-feita: repensar a reforma, reformar o pensamento. Rio de Janeiro: Bertrand Brasil, 2010.
MORIN, Edgar. A comunicação pelo meio (teoria complexa da comunicação). Revista Famecos, Porto Alegre, v. 1, n. 20, p. 7-12, abr. 2003.

MORIN, Edgar. Introdução ao pensamento complexo. Rio Grande do Sul: Sulinas, 2005.

MORIN, Edgar. O método 1: a natureza da natureza. Rio Grande do Sul: Sulinas, 2008.

MORIN, Edgar. O problema epistemológico da complexidade. Portugal: Publicações Europa-América, 2002.

PETRAGLIA, Izabel. Edgar Morin: a educação e a complexidade do ser e do saber. Rio de Janeiro: Vozes, 2002. 
